\title{
Middle Ear Effusion Interleukin-6 and Interleukin-8 levels could Differentiate between Bacterial and Non- Bacterial Acute Otitis Media and Help to Identify the Type of Infecting Bacteria
}

\author{
Thanaa Hamed, Mamdouh Abadier, \& Mohamed Shindy* \\ Departments of Medical Biochemistry \& Otorhinolaryngology* \\ Faculty of Medicine, Benha University
}

\begin{abstract}
This study aimed to investigate the middle ear effusion (MEE) levels of interleukin-6 (IL-6) and IL-8 in children with acute otitis media (AOM) and their relation to its etiology and type of infecting bacteria as a trial to define a faster diagnostic modality than traditional culture and sensitivity test so as to early initiate therapy. The study included 70 children; 44 males and 26 females, with a mean age of $19.3 \pm 8$ months; 50 patients had unilateral and 20 bilateral AOM ( $n=90$ ears). The diagnosis of AOM was based on presence of fever, irritability or earache and signs of inflammation of the tympanic membrane. The presence of MEE was documented by tympanocentesis and MEE samples were obtained for culture to define the offending pathogen, cytological examination to grade it according to number of polymophonuclear leucocytes (PNL) and ELISA estimation of the levels of IL-6 and IL-8. Sensitivity and specificity of MEE IL-6 and IL-8 levels for differentiation between bacterial and nonbacterial cases and identification of infecting bacteria were evaluated using the receiver operating characteristic (ROC) curve analysis judged by the area under the curve (AUC). Bacteriological examination identified the infective pathogen in 61 samples (67.7\%) and no bacterial infection in 29 samples (32.3\%). Combined infection with Haemophilus influenzae (H. inf.) and Streptococcus pneumoniae (S. pn.) was detected in 12 samples. However, single pathogen infection was detected in 49 samples; $H$. inf in 35 samples, S. pn in 11 samples, Moraxella catarrhalis in 2 samples and S. pyogenes in one sample. Effusion was serous in 52, mucoid in 28 and purulent in 10 effusions. Nine samples were grade I, 35 were grade II, 29 samples were grade III and 17 samples were grade IV. There was a significant $(p<0.05)$ increase of MEE IL-6 level in samples with positive culture compared to samples with negative culture. Also, there was a significant $(p<0.05)$ increase in MEE IL-6 levels in samples positive for $S$. pn. compared to its levels estimated in samples infected with $H$. inf. or by both pathogens. Mean MEE IL-8 level was significantly $(p<0.05)$ elevated in samples with positive culture compared to levels estimated in samples with negative culture. Moreover, MEE IL-8 levels in samples positive for $H$. inf. were significantly $(p<0.05)$ elevated compared to levels estimated in samples positive for $S$. $p n$. and non-significantly ( $p>0.05)$ elevated compared to levels estimated in samples with mixed infection. ROC curve analysis revealed that estimation of MEE levels of both IL-6 and IL-8 are specific for the presence of bacterial AOM with AUC $=0.832$ \&
\end{abstract}


0.897, respectively. Elevated MEE level of IL-6 could differentiate between $H$. inf. and S. pn. infection with high specificity with $A U C=0.758$, while $I L-8$ was more sensitive indictor of $H$. inf. infection with $A U C=0.363$. It may be concluded that AOM is associated with elevated MEE levels of $I L-6$ and $I L-8$ which may suggest a role imposed by these cytokines in pathogenesis of AOM. The elevated levels of both cytokines could differentiate bacterial from non-bacterial cases with high specificity. Elevated MEE level of IL-6 may be specific for S. pn infection, while elevated IL-8 levels may be a sensitive for $H$. inf. infection

\section{INTRODUCTION}

Otitis media is, next to the common cold, the most commonly diagnosed illness in children and myringotomy with tympanostomy tube insertion (M\&T) is the most common surgical operation among children beyond the newborn period ${ }^{(\mathbf{1})}$. Current practice guidelines recommend M\&T for young children in whom middle-ear effusion (MEE) has persisted for 3 months or for 4 to 6 months provided that a bilateral hearing loss of $\geq 20$ decibel is present ${ }^{(2)}$. The recommendation stems from concern that prolonged middleear inflammation might result in untoward otologic or audiologic sequelae, and that the conductive hearing loss that accompanies MEE might result in later impairments of cognition, language, speech, or psychosocial development ${ }^{(3)}$.

The natural history of local inflammatory responses in middle ear infection has been investigated with animal otitis media models infected with clinically important bacterial species. Streptococcus pneumoniae is the most prevalent middle ear bacterial pathogen, cultured from approximately $40 \%$ of MEF samples from children with acute otitis media $(\mathrm{AOM})^{(4)}$ and $7 \%$ of $\mathrm{MEF}$ samples from children with chronic otitis media with effusion (OME) ${ }^{(5)}$.

Despite the many antibiotics available for its treatment, therapeutic failures, persistence of middle ear fluid effusion, and recurrences of the disease occur frequently. A better understanding of the pathogenesis and the inflammatory process associated with AOM might be helpful in developing more effective strategies for the management and prevention of this disease ${ }^{(6)}$.

The inflammatory process associated with acute otitis media is complex and involves many factors, including bacteria, viruses, macrophages, lysozyme and oxidative metabolic products and cytokines ${ }^{(7)}$. Cytokines are glycoproteins synthesized by a variety of cells and are known to modulate cellular functions in inflammatory and immune reactions. Interleukin-1 $\beta$ (IL$1 \beta$ ) is known to induce synthesis of tumor necrosis factor alpha (TNF- $\alpha$ ) and to cause hemodynamic changes and fever ${ }^{(8)}$. Previous findings suggest that an activated local immune system is present in the middle ear fluid of patients with OME and considerable amounts of TNF- $\alpha$, IL-1 $\beta$, IL-2, and interferon- $\gamma$ were found in the middle ear fluid of children with OME; higher TNF- $\alpha$ concentrations were found in older children and in 
those patients who underwent multiple tympanostomies $^{(9)}$.

Interleukin-6 is $\quad a$ proinflammatory cytokine that plays a key role in the acute phase reaction. IL-6 is a potent inducer of C-reactive protein and has been shown in vitro and in animal models to inhibit TNF$\alpha^{(\mathbf{1 0})}$. Several authors have reported that IL-6 is a sensitive and reliable marker of neonatal bacterial infection $^{(11)}$, but no reports of the value of IL-6 as a possible marker for bacterial AOM are available ${ }^{(\mathbf{1 2})}$.

IL-8 is produced predominantly by monocytes, macrophages, and endothelial cells in response to stimuli such as lipopolysaccharide and TNF$\alpha{ }^{\left({ }^{(3)}\right.}$. It acts as a chemotactic factor for neutrophils, T lymphocyte subsets, and basophils. In addition, it activates neutrophils to release lysosomal enzymes, undergo a respiratory burst and also increases the adherence of neutrophils to endothelial cells ${ }^{(\mathbf{1 4})}$. The endotoxin of Gram negative bacteria was found to be a potent amplifier of IL-8 production in middle ear fluid samples from children with chronic otitis media with effusion ${ }^{(\mathbf{1 5})}$.

The current study aimed to investigate the middle ear effusion levels of IL-6 and IL-8 in children with acute otitis media and their relation to its etiology and type of infecting bacteria as a trial to define a faster diagnostic modality than traditional culture and sensitivity test so as to early initiate therapy.

\section{PATIENTS \& METHODS}

The current study was conducted at Otorhinolaryngology Department, University Hospital in conjunction with Medical Biochemistry Department, Faculty of Medicine, Benha University. The study included children aged 3-36 months with acute otitis media. All enrolled patients had an acute illness since $\leq$ seven day's duration; they had no spontaneous perforation and no tympanostomy tubes present and did not receive antibiotics during the preceding week. The diagnosis of AOM was based on symptoms of fever, irritability or earache and signs of inflammation of the tympanic membrane (red or yellow color or bulging). At enrollment, the presence of MEE was documented by tympanocentesis and middle ear fluid sample was obtained.

\section{Sample Collection}

The procedures were conducted under general inhalational anesthesia. Antisepsis of the ear canal before tympanocentesis was done with $70 \%$ alcohol instilled for one minute. After removal of the alcohol by suction, topical anesthesia was applied with equal mixture of $0.1 \%$ epinephrine and $4 \%$ lidocaine hydrochloride. After iontophoretic anesthesia, the anesthetic agents were washed out with sterile saline solution from the external ear canal and with the use of a 20 gauge spinal needle attached to a $1.0 \mathrm{ml}$ sterilized tuberculin syringe, the anteroinferior portion of the intact tympanic membrane was punctured and the fluid was immediately aspirated into the sterile syringe by suction and divided into 3 parts

1. A part of MEE sample was applied to a sterile swab, which was sent for bacteriological culture in transport medium (MW173 Amies medium; Transwab; Medical Wire and Equipment, Potley, UK) for 
processing within 12 hours at the Clinical Pathology Laboratory ${ }^{(\mathbf{1 6})}$.

2. A second part used for cytological examination: following centrifugation of MEE samples, the pellets were suspended with phosphate-buffered saline $(\mathrm{pH} 7.4$, $0.01 \mathrm{~mol} / \mathrm{l}$ ) and applied to the centrifuge at $1000 \mathrm{rpm}$ for 10 minutes. Cell components were fixed with $6 \%$ formaldehyde. After staining with hematoxylin-eosin, the specimens were examined under light microscopy and the number of PNL and mononuclear cells were counted. On the basis of the cytologic findings of the MEE, the samples were classified into 4 grades according to the distribution of PNL: in grade I, PNL $>80 \%$; grade II, PNL 50-80\%; grade III, PNL $20-50 \%$ and in grade IV, PNL $<20 \%$.

3. A third part was centrifuged at 3000 rpm for 10 minutes and supernatant was collected and stored at $-70^{\circ} \mathrm{C}$ to be used for estimation of IL-8 and IL-6 using ELISA assay (Quantikine" kit; R\&D Systems, Minneapolis, Minnesota, USA) for IL-8, ${ }^{(17)}$ and IL-6, ${ }^{(18)}$. The results are reported as mean (SD) IL-8 and IL-6 concentration (pg/ml). The minimum detectable level is
$10 \mathrm{pg} / \mathrm{ml}$ for IL-8 and $0.7 \mathrm{pg} / \mathrm{ml}$ for IL-6.

\section{Statistical analysis}

Obtained data were presented as mean \pm SD and ranges and were analyzed using un paired t-test. Sensitivity and specificity for differentiation between bacterial and non-bacterial cases and identification of infecting bacteria were evaluated using the ROC curve analysis judged by the area under the curve. Statistical analysis was conducted using the SPSS (Version 10, 2002) for Windows statistical package. $\mathrm{P}$ value $<0.05$ was considered statistically significant.

\section{RESULTS}

The study comprised 70 patients; 44 males and 26 females, with a mean age of $19.3 \pm 8$; range 3-35 months. There were 50 patients with unilateral and 20 bilateral otitis media, thus the study included 90 middle ear fluid samples. There was a non-significant $(\mathrm{P}>0.05)$ difference between patients categorized according to laterality of otitis media as regards sex and age distribution and in comparison to control group, (Table 1).

Table (1): Patients' clinical data

\begin{tabular}{|l|c|c|c|}
\hline Data & Number & Age (years) & Sex (M:F) \\
\hline Total & 70 & $19.3 \pm 8(3-35)$ & $44: 26$ \\
\hline Unilateral OME & 50 & $18.7 \pm 7.2(4-35)$ & $32: 18$ \\
\hline Bilateral OME & 20 & $19.2 \pm 8.1(3-35)$ & $12: 8$ \\
\hline
\end{tabular}

$M: F=$ Male: Female ratio

Bacteriological examination of the obtained samples could identify the infective pathogen in 61 samples
$(67.7 \%)$ and no bacterial infection could be identified in the other 29 samples (32.3\%), (Fig. 1). 
Concomitant infection was detected in 12 culture positive samples with the infecting pathogens were Haemophilus influenzae and Streptococcus pneumoniae; 35 cultures were $H$. influenzae (all untypeable) positive, 11 were $S$. pneumoniae positive, two Moraxella catarrhalis, and one S. pyogenes, (Table 2).

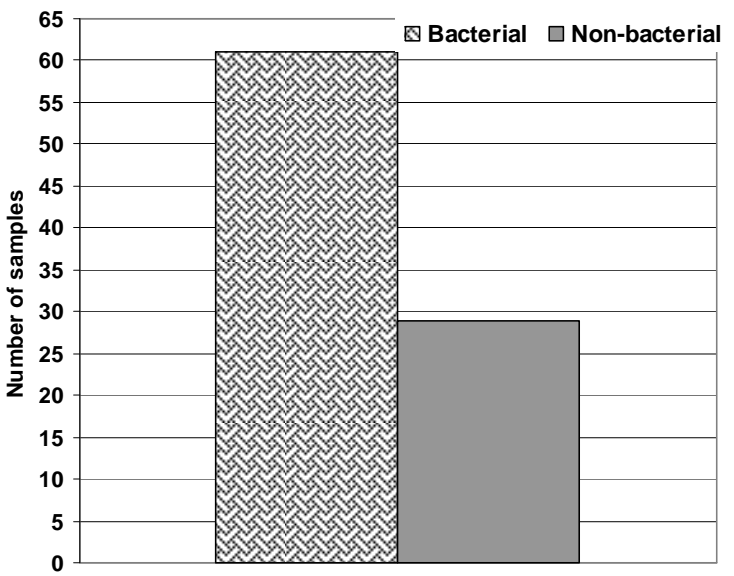

Fig. (1): Middle ear effusion samples' distribution according to results of bacteriologic examination

Table (2): Results of bacteriological examination

\begin{tabular}{|c|c|c|c|}
\hline \multicolumn{3}{|l|}{ Result } & Number (\%) \\
\hline \multicolumn{3}{|l|}{ Negative culture } & $29(32.3 \%)$ \\
\hline \multirow[t]{5}{*}{ Positive culture } & \multicolumn{2}{|c|}{ Combined pathogen } & $12(13.3 \%)$ \\
\hline & \multirow[t]{4}{*}{ Single pathogen } & H. influenzae & $35(38.9 \%)$ \\
\hline & & S. pneumoniae & $11(12.2 \%)$ \\
\hline & & Mor. catarrhalis & $2(2.2 \%)$ \\
\hline & & S. pyogenes & $1(1.1 \%)$ \\
\hline \multicolumn{3}{|l|}{ Total } & $90(100 \%)$ \\
\hline
\end{tabular}

Patients were categorized according to the macroscopic MEE characters; there were $52(57.8 \%)$ serous effusions, $28(31.1 \%)$ mucoid effusions and $10(11.1 \%)$ purulent effusions, (Fig. 2). Categorization of samples according to grade of PNL count showed the inclusion of $9(12 \%)$ samples in grade I with mean PNL count of $87.1 \pm 30 \%, \quad 35 \quad(33.3 \%)$ samples in grade II with mean count of $66.1 \pm 32.4 \%$; $29(32.8 \%)$ samples in grade III with mean count of $30 \pm 15.2 \%$, and $17(21.9 \%)$ samples in grade IV with mean count of $13.4 \pm 6 \%$, (Table 3, Fig. 3). 


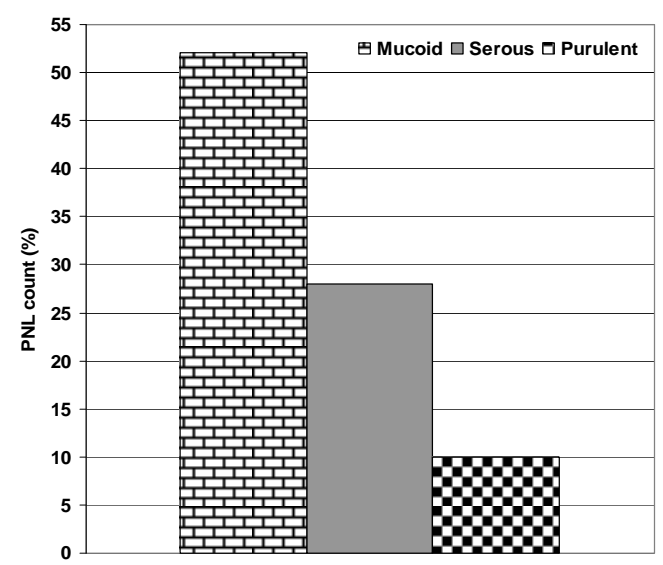

Fig. (2): Samples' distribution according to macroscopic characters of $\mathrm{MEE}$

Table (3): Samples' distribution according to results of microscopic grading according to PMN count of MEE

\begin{tabular}{|l|c|c|}
\hline Grade & Number (\%) & PMN Count (\%) \\
\hline Grade I & $9(10 \%)$ & $87.1 \pm 30$ \\
\hline Grade II & $35(38.9 \%)$ & $66.1 \pm 32.4$ \\
\hline Grade III & $29(32.2 \%)$ & $30 \pm 15.2$ \\
\hline Grade IV & $17(18.9 \%)$ & $13.4 \pm 6$ \\
\hline
\end{tabular}

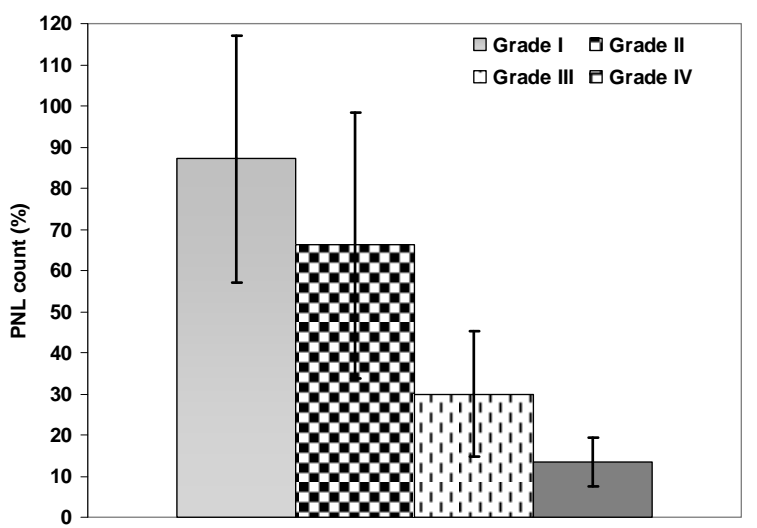

Fig. (3): Categorization of samples according to grade of PNL count

Mean total MEE IL-6 level was $28.39 \pm 20$; range: $12-115 \mathrm{pg} / \mathrm{ml}$, there was a significant $(\mathrm{p}<0.05)$ increase of MEE IL-6 in samples with positive culture (33.74 \pm 22.18 ; range: 12-115 $\mathrm{pg} / \mathrm{ml}$ ) compared to samples with negative culture $(17.14 \pm 4.56$; range: $12-26 \mathrm{pg} / \mathrm{ml})$. Moreover, there was a significant $(\mathrm{p}<0.05)$ increase of MEE IL-6 level in samples positive for $S$. 
pneumoniae (67.55 \pm 30.61 ; range: 23 115) compared to levels estimated in samples infected with $H$. influenzae (25.54 \pm 8.96 ; range: $12-42 \mathrm{pg} / \mathrm{ml})$ or by both pathogens $(30.5 \pm 12$; range: 15-59 pg/ml), (Fig. 4). Similarly, the mean total MEE IL-8 level was significantly $(p<0.05)$ elevated in samples with positive culture (9380 $\pm 5690 ; \quad$ range: 2360-29750 $\mathrm{pg} / \mathrm{ml}$ ) compared to levels estimated in samples with negative culture (5250 $\pm 2140 ; \quad$ range: 2360-8950 $\mathrm{pg} / \mathrm{ml}$ ), moreover, MEE IL-8 levels in samples positive for $H$. influenzae (13970 \pm 6666 ; range: 5250-29750 $\mathrm{pg} / \mathrm{ml})$ were significantly $(\mathrm{p}<0.05)$ elevated compared to levels estimated in samples positive for $S$. pneumoniae $(8080 \pm 2010 ; \quad$ range: $5250-11200$ $\mathrm{pg} / \mathrm{ml})$ and non-significantly $(\mathrm{p}>0.05)$ elevated compared to levels estimated in samples with mixed infection (10675 \pm 4190 ; range: $(5250-20650$ pg/ml), (Table 4, Fig. 5).

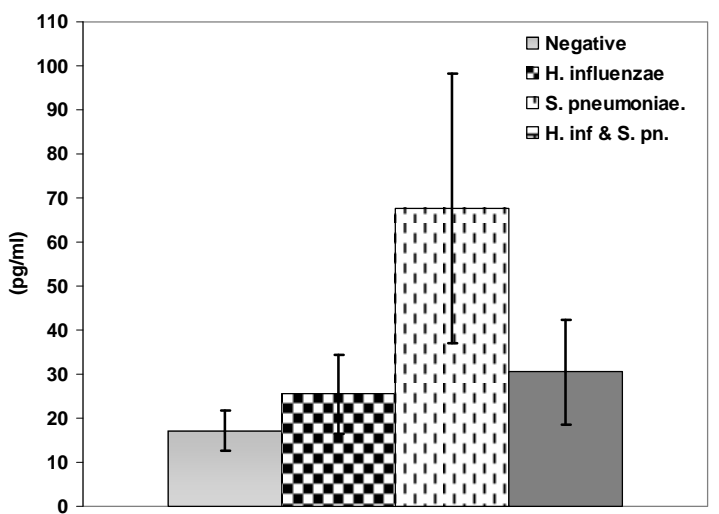

Fig. (4): Mean ( $\pm S D)$ MEE IL-6 levels in obtained samples categorized according to bacterial culture

Table (4): Mean ( \pm SD) IL-6 and IL-8 levels in MEE categorized according to result of bacteriological examination

\begin{tabular}{|c|c|c|c|c|}
\hline \multicolumn{3}{|c|}{ Culture result } & IL-6 (pg/ml) & IL-8 (ng/ml) \\
\hline \multicolumn{3}{|c|}{ Total $(n=90)$} & $28.39 \pm 20(12-115)$ & $9.38 \pm 5.69(2.36-29.75)$ \\
\hline \multicolumn{3}{|c|}{ Negative culture $(n=29)$} & $17.14 \pm 4.56(12-26)$ & $5.25 \pm 2.14(2.36-8.95)$ \\
\hline \multirow{4}{*}{$\begin{array}{l}\text { Positive } \\
\text { culture }\end{array}$} & \multicolumn{2}{|c|}{ Total $(n=61)$} & $33.74 \pm 22.18(12-115)^{*}$ & $11.345 \pm 5.8(5.25-29.75)^{*}$ \\
\hline & \multicolumn{2}{|c|}{ Combined pathogen $(n=12)$} & $30.5 \pm 12(15-59)^{* \dagger}$ & $10.675 \pm 4.19(5.25-20.65)^{*}$ \\
\hline & \multirow{2}{*}{$\begin{array}{l}\text { Single } \\
\text { pathogen }\end{array}$} & H. inf $(\mathrm{n}=35)$ & $25.54 \pm 8.96(12-42)^{*} \dagger$ & $13.97 \pm 6.666(5.25-29.75) * \dagger$ \\
\hline & & S. $p n(n=11)$ & $67.55 \pm 30.61(23-115)^{*}$ & $8.08 \pm 2.01(5.25-11.2)^{*}$ \\
\hline
\end{tabular}




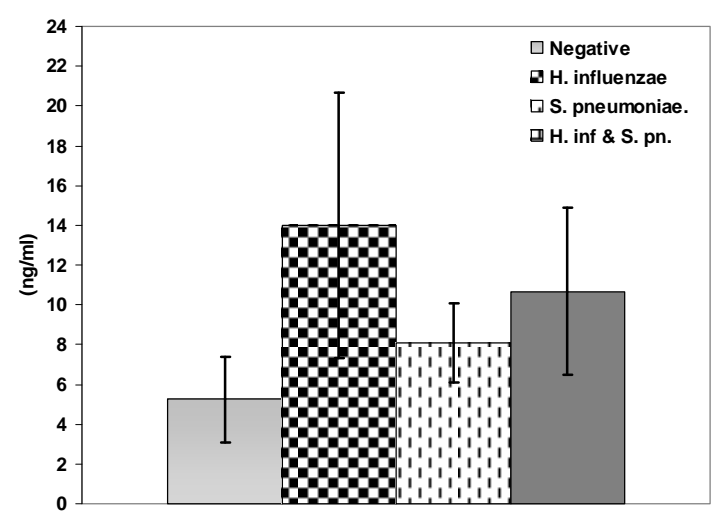

Fig. (5): Mean ( $\pm S D)$ MEE IL-8 levels in obtained samples categorized according to bacterial culture

Using ROC curve analysis to evaluate the sensitivity and specificity of estimation of MEE IL- 6 and IL- 8 to differentiate between bacterial and non-bacterial cases of AOM showed that both are specific for the presence of bacterial AOM with high specificity as determined by $\mathrm{AUC}=0.832 \& 0.897$, respectively
(Fig. 6). However, Elevated MEE level of IL-6 could differentiate between $H$. influenzae and $S$. pneumoniae infection with high specificity with $\mathrm{AUC}=0.758$, while IL-8 was more sensitive indictor of $H$. influenzae infection with $\mathrm{AUC}=0.363$, (Fig. 7).

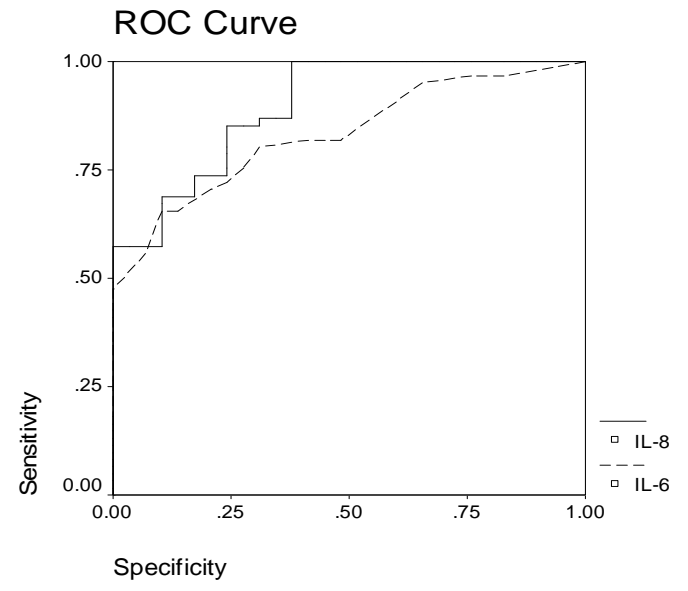

Fig. (6): ROC curve analysis of diagnostic sensitivity \& specificity of estimation of $M E E I L-6$ and $I L-8$ for differentiation between bacterial and non-bacterial cases of AOM 


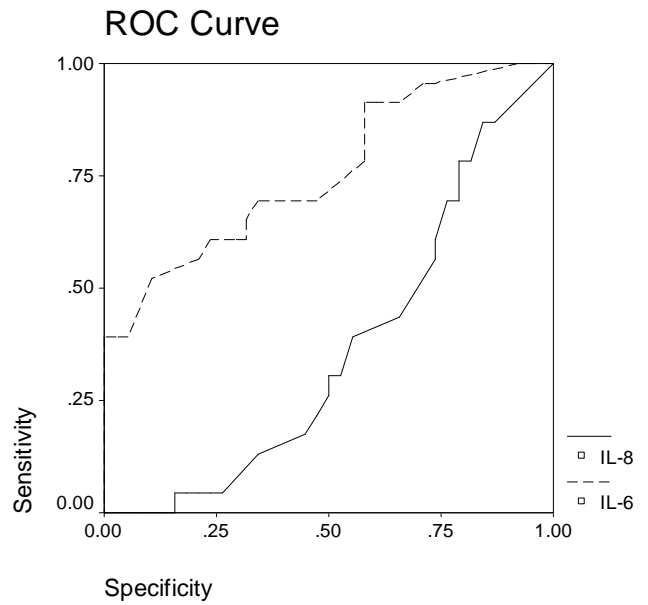

Fig. (7): ROC curve analysis of diagnostic sensitivity \& specificity of estimation of MEE IL-6 and IL-8 for differentiation between cases infecting pathogen $(H$. influenzae or S. pneumoniae).

\section{DISCUSSION}

More than half of all children experience at least one episode of acute otitis media before the age of 3 years. The incidence of this type of infection is highest among children under 2 years of age and appears to have increased since the $1970 \mathrm{~s}^{(\mathbf{1 9 )}}$. The issues of increasing antimicrobial resistance and the purported favorable natural history of untreated AOM have sustained the debate over whether antimicrobial therapy should be given immediately or if "watchful waiting" would substantially alter outcomes for clinically diagnosed acute otitis media ${ }^{(6)}$.

Bacterial culture of the MEE is currently the only reliable method to distinguish bacterial from nonbacterial etiology of AOM. In virtually all cases, this requires tympanocentesis, which is not feasible in everyday clinical practice. Even if MEF is obtained, the results of the bacterial culture are not readily available, and in most cases empirical antibiotic therapy is started before knowledge of the etiologic agent ${ }^{(20)}$. In the current study, culture identified the infective pathogen in 61 samples $(67.7 \%)$ with $H$. inf. and $S$. pn. were the most common infecting bacteria; while no bacterial infection could be identified in the other 29 samples (32.3\%). These findings go in hand with $\mathbf{L i}$ et al. $^{\text {(20) }}$ who reported that $H$. inf. and $S$. $p n$. are the most common causative organisms and with Drake-Lee et al. $^{\text {(21) }}$ who reported that the four bacteria Streptococcus pneumoniae, Haemophilus influenza, Staphylococcus aureus and Branhamella catarrhalis cause $60 \%$ of the infections whereas S. pneumoniae accounts for up to $35 \%$ of acute otitis media.

There were $52(57.8 \%)$ serous effusions, $28 \quad(31.1 \%) \quad$ mucoid 
effusions and $10(11.1 \%)$ purulent effusions. Categorization of samples according to grade of PNL count showed the inclusion of $9(12 \%)$ samples in grade I, $35(33.3 \%)$ samples in grade II, $29(32.8 \%)$ samples in grade III and $17(21.9 \%)$ samples in grade IV. These figures coincided with the sequence of etiogenesis of OME in children described by Kubba et al. ${ }^{(22)}$ and Chung et al. ${ }^{(23)}$ that the primary event is inflammation of the middle ear mucosa, usually due to the presence of bacteria leading to the release of inflammatory mediators, which causes secretion of a mucin-effusion by upregulating mucin genes. Prolonged stimulation of the inflammatory response and poor mucociliary clearance lead to persistence of middle ear fluid that becomes purulent.

There was a significant increase of MEE IL-6 in samples with positive culture compared to samples with negative culture with a significant increase in samples positive for $S$. $p n$. compared to levels estimated in samples infected with $H$. inf. or by both pathogens. Similarly, the mean total MEE IL-8 level was significantly elevated in samples with positive culture compared to levels estimated in samples with negative culture and in samples positive for $H$. inf. compared to levels estimated in samples positive for $S$. $p n$. Using ROC curve analysis, both MEE IL-6 and IL-8 were specific for the presence of bacterial AOM. However, elevated MEE level of IL-6 could differentiate between $H$. inf. and $S$. pn. infection with high specificity while IL-8 was more sensitive indictor of $H$. inf. infection.

These results agreed with Sato et al. ${ }^{(24)}$ who reported that IL-6 concentrations correlated significantly with total inflammatory cell numbers in MEE, and with MEE neutrophil concentration. These results illustrated the fact that IL- 6 is a proinflammatory cytokine secreted by neutrophils that was considered as acute phase reactant and explain the significant increase of IL-6 in these cases with acute inflammation. Also, Dong et al. $^{\text {(25) }}$ reported that IL-6 and IL-8 might be important mediators in MEE secretion in secretory otitis media and IL-6 and IL- 8 might participate in the defensive reaction of the organism during the early stages. Russo et al. ${ }^{\text {(26) }}$ found the concentrations of interleukin-6 were greater in the MEE of the children and were greater in serous than in mucoid MEE and reported that concentrations of IL-6 in MEE correlated with the degree of hearing loss.

The increased levels of IL- 6 and IL-8 in MEE of bacterial cases could be attributed to the neutrophil influx associated with bacterial infection and agreed with Appelberg, ${ }^{(27)}$ and Condos et al. ${ }^{\text {(28) }}$ who reported that the earliest response to mycobacteria is primarily an influx of polymorphonuclear neutrophils (PMN) via the action of chemotactic factors. Also, increased levels of estimated cytokines in cases infected by $H$. inf. and $S$. pn. go in hand with that reported by Ribeiro-Rodrigues et al. $^{\text {(29) }}$ who found TNF-alpha, IL-8 and IL-6 were readily detected in sputum from TB patients at baseline and responded to anti-TB therapy and 
were elevated in sputum from patients with bacterial pneumonia.

Also, the obtained results agreed with the results of experimental model of otitis media of Barrett et al. ${ }^{(\mathbf{3 0})}$ who reported that exposure to bacterial lipopolysaccharide activates intercellular adhesion molecule-1 receptors and NF-kappaB followed by release of IL-8; an autocrine pathway that is established through activation of TNF alpha and IL-1beta. Also, Smirnova et al. $^{(31)}$ reported that cytokine and cellular patterns of effusions may reflect stages of middle ear inflammation and their local interplay is likely to play a crucial role in the switching of inflammation in the chronic stage and concluded that early identification of the cytokine and cellular patterns of effusions can be helpful in directing the clinical treatment of otitis media with effusion.

It could be concluded that AOM is associated with elevated MEE levels of IL-6 and IL-8 suggesting a role imposed by these cytokines in pathogenesis of AOM. The elevated levels of both cytokines could differentiate bacterial from nonbacterial cases with high specificity. Also, elevated MEE level of IL-6 is specific for $S$. pneumoniae infection, while elevated IL-8 levels is a sensitive for $H$. influenzae infection, so estimation of MEE levels of both cytokines may provide a faster diagnostic approach that aid for early initiation of therapeutic regimens.

\section{REFERENCES}

1. Guven M, Bulut $Y$, Sezer T, Aladag I, Eyibilen A \& Etikan I
(2006): Bacterial etiology of acute otitis media and clinical efficacy of amoxicillinclavulanate versus azithromycin. Int. J. Pediatr. Otorhinolaryngol.; 70(5):915-23.

2. Lous J, Burton MJ, Felding JU, Ovesen T, Rovers MM \& Williamson I (2005): Grommets (ventilation tubes) for hearing loss associated with otitis media with effusion in children. Cochrane Database Syst. Rev.; 25(1): CD001801.

3. Hydén D, Akerlind B \& Peebo $M$ (2006): Inner ear and facial nerve complications of acute otitis media with focus on bacteriology and virology. Acta Otolaryngol.;126(5):460-6.

4. Leibovitz E, Satran R, Piglansky L, Raiz S, Press J, Leiberman A \& Dagan $\mathbf{R}$ (2003): Can acute otitis media caused by Haemophilus influenzae be distinguished from that caused by Streptococcus pneumoniae? Pediatr. Infect. Dis. J.; 22(6): 509-15.

5. Arguedas A, Dagan R, Soley C, Loaiza C, Knudsen K, Porat N, Perez A, Brilla E \& Herrera ML (2003): Microbiology of otitis media in Costa Rican children, 1999 through 2001. Pediatr. Infect. Dis. J.; 22(6): 509-15.

6. Le Saux N, Gaboury I, Baird M, Klassen TP, MacCormick J, Blanchard C, Pitters C, Sampson M \& Moher D (2005): A randomized, double-blind, placebo-controlled noninferiority trial of amoxicillin for clinically diagnosed acute otitis media in 
children 6 months to 5 years of age. CMAL, 172(3): 335-41.

7. Fergie JE \& Purcell K (1998): The role of inflammatory mediators and anti-inflammatory drugs in otitis media. Pediatr. Ann.; 27: 76-81.

8. Yellon RF, Doyle WJ, Whiteside TL, Diven WF, March AP \& Fireman P (1995): Cytokines, immunoglobulins, and bacterial pathogens in middle ear effusions. Arch. Otolaryngol. Head Neck Surg. 121:865-869.

9. Nerkio-Makela M, Teppo AM \& Meri S (2000): Complement C3 cleavage and cytokines interleukin-1beta and tumor necrosis factor-alpha in otitis media with effusion. Laryngoscope.; $110(10 \mathrm{Pt} \quad 1)$ : 1745-9.

10. Kishimoto T (1989): The biology of interleukin-6. Blood; 74:1-10.

11. Messer J, Eyer $D$, Donato $L$, Gallati H, Matis J \& Simeoni U (1996): Evaluation of interleukin6 and soluble receptors of tumor necrosis factor for early diagnosis of neonatal infection. J. Pediatr.; 129:574-80.

12. Panero A, Pacifico L, Rossi N, Mancuso G, Stegagno $\mathbf{M}$, Chiesa C (1997): Interleukin 6 in neonates with early and late onset infection. Pediatr. Infect. Dis. J.; 16:370-5.

13. Baggiolini $M$, Walz A \& Kunkel SL (1989): Neutrophilactivating peptide 1/interleukin 8 , a novel cytokine that activates neutrophils. J. Clin. Invest.; 84: 1045-9.

14. Mukaida N, Harada A, Yasumoto K \& Matsushima $\mathrm{K}$
(1992): Properties of proinflammatory cell typespecific leukocyte chemotactic cytokines, interleukin-8 (IL-8) and monocyte chemotactic and activating factor (MCAF). Microbiol. Immunol.; 36: 773-89.

15. Ovesen $T$ \& Ledet $T$ (1992): Bacteria and endotoxin in middle ear fluid and the course of secretory otitis media. Clin. Otolaryngol.; 17: 531-4.

16. Dagan $R$, Abramson $O \&$ Leibovitz E (1997): Bacteriologic response to oral cephalosporins: are established susceptibility breakpoints appropriate in the case of acute otitis media? J. Infect. Dis.; 176: 1253-9.

17. Prins JM (1995): Antibioticinduced endotoxin release in patients with gram-negative urosepsis: a double-blind study comparing imipenem and ceftazidime. J. Infect. Dis.; 886: 172.

18. Engvall $E$ \& Perlmann $P$ (1972): Enzyme-linked immunosorbent assay. Quantitation of specific antibodies by enzyme-labeled anti-immunoglobulin in antigencoated tubes. J. Immunol.; 109: 129-35.

19. Joki-Erkkila VP, Laippala $P$ \& Pukander J (1998): Increase in paediatric acute otitis media diagnosed by primary care in two Finnish municipalities: 1994-5 versus 1978-9. Epidemiol. Infect.; 121(3):529-34.

20. Li WC,Chiu NC, Hsu CH, Lee KS, Hwang HK \& Huang FY (2001): Pathogens in the middle 
ear effusion of children with persistent otitis media: implications of drug resistance and complications. J. Microbiol. Immunol. Infect.; 34(3): 190-4.

21. Drake-Lee AB, Hughes RG \& Dunn C (2003): Serum IgA and $\mathrm{IgG}$ functional antibodies and their subclasses to Streptococcus pneumoniae capsular antigen found in two aged-matched cohorts of children with and without otitis media with effusion. Clin. Otolaryngol. Allied Sci.; 28(4):335-40.

22. Kubba H, Pearson JP \& Birchall JP (2000): The aetiology of otitis media with effusion: a review. Clin. Otolaryngol.; 25: 181-94.

23. Chung MH, Choi JY, Lee WS, Kim HN \& Yoon JH (2002): Compositional difference in middle ear effusion: mucous versus serous. Laryngoscope; 112(1): 152-5.

24. Sato K, Kawana M, Nonomura N \& Nakano Y (1999): Course of IL-1beta, IL-6, IL-8, and TNFalpha in the middle ear fluid of the guinea pig otitis media model induced by nonviable Haemophilus influenzae. Ann. Otol. Rhinol. Laryngol; 108(6):559-63.

25. Dong W, Li Z \& Zhou S (2001): Superoxide dismutase and cytokines in otitis media with effusion. Lin. Chuang. Er. Bi. Yan. Hou. Ke. Za. Zhi.; 15(10):452-4.

26. Russo E, Smith CW, Friedman EM, Smith EO \& Kaplan SL
(2004): Cell adhesion molecules and cytokines in middle ear effusions in children with or without recent acute otitis media. Otolaryngol. Head Neck Surg.; 130(2): 242-8.

27. Appelberg $R \quad$ (1992): Mycobacterial infection primes $\mathrm{T}$ cells and macrophages for enhanced recruitment of neutrophils. J. Leukoc. Biol.; 57: 472-7.

28. Condos R, Rom WN, Liu YM \& Schluger NW (1998): Local immune responses correlate with presentation and outcome in tuberculosis. Am. J. Respir. Crit. Care Med.; 157: 729-35.

29. Ribeiro-Rodrigues $R$, Resende Co T, Johnson JL, Ribeiro F, Palaci M, Sa RT, Maciel EL, Pereira Lima FE, Dettoni V, Toossi Z, Boom WH, Dietze R, Ellner JJ \& Hirsch CS (2002): Sputum cytokine levels in patients with pulmonary tuberculosis as early markers of mycobacterial clearance. Clin. Diagn. Lab. Immunol. 2002 Jul;9(4):818-23.

30. Barrett TQ, Kristiansen LH \& Ovesen T (2003): NF-kappaB in cultivated middle ear epithelium. Int. J. Pediatr. Otorhinolaryngol.; 67(8): 895-903.

31. Smirnova MG, Birchall JP \& Pearson JP (2005): Evidence of T-helper cell 2 cytokine regulation of chronic otitis media with effusion. Acta Otolaryngol.; 125(10): 1043-50. 


\section{مستوى الأنترلوكيين- يمكن من التمييز بين التهاب الأذن الوسطى الحاد البكتيري من غير البكتيري

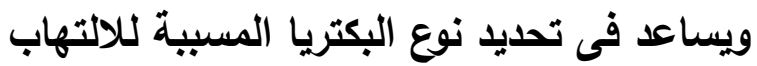

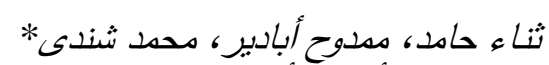

أقسام الكيمياء الحيوية الطبية، الأذن والأنف والحنجرة محدر مكلية الطب - جامعة بنها

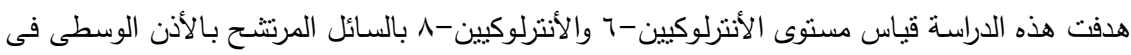

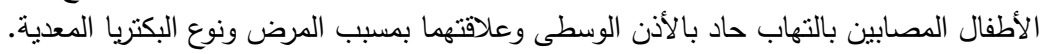

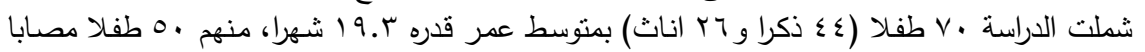

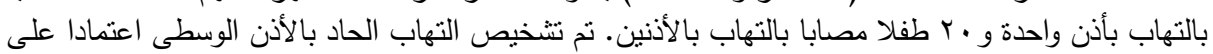

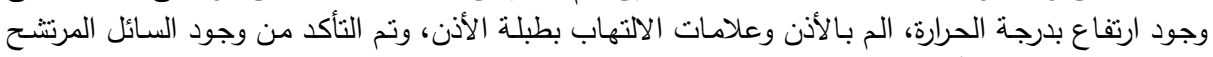

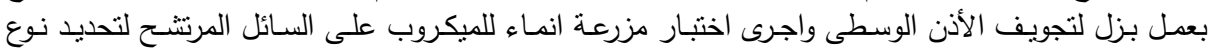

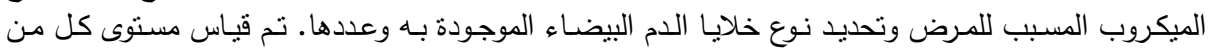

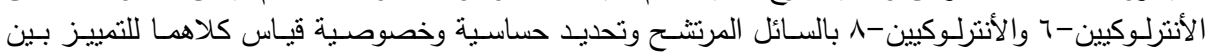

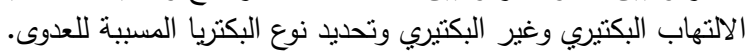

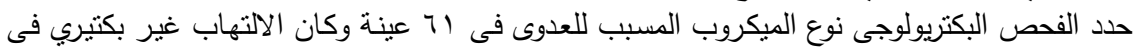

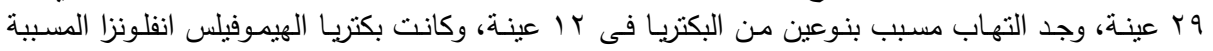

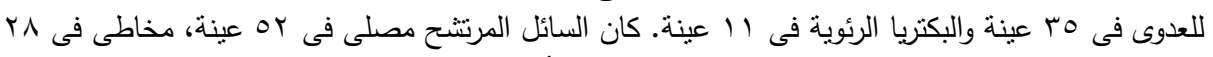

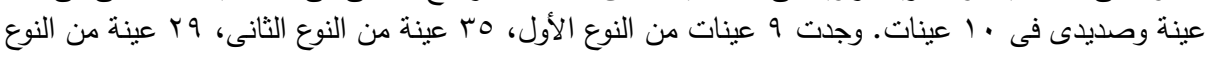

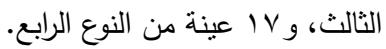

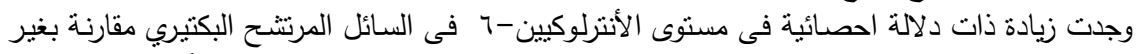

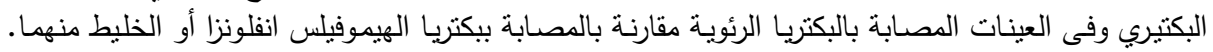

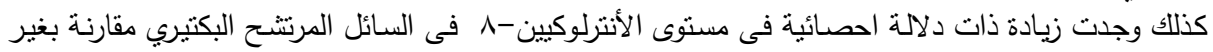

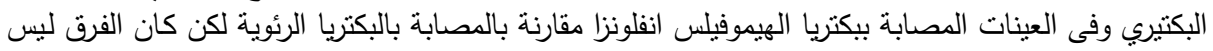

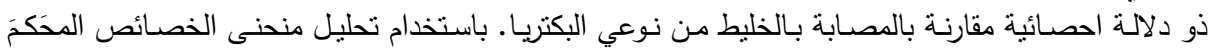

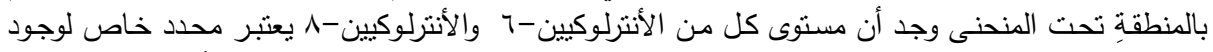

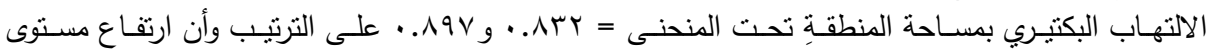

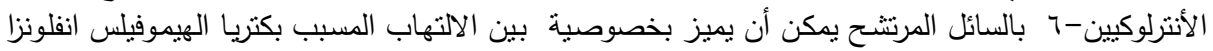

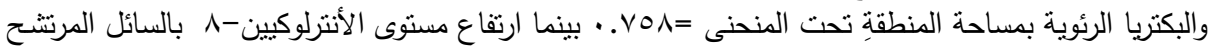

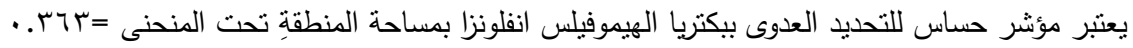

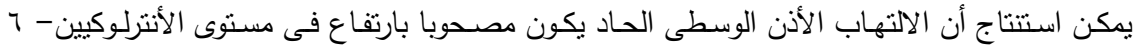

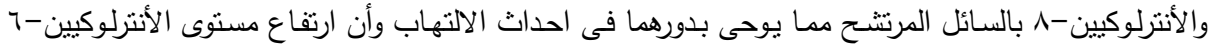

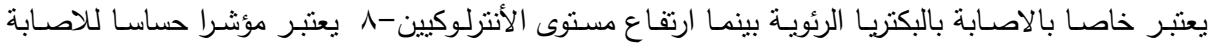
ببكتريا الهيموفيلس انفلونزا. 